JKEP

Vol 6, No 1 (2021)

ISSN: 2338-9095 (Print)

ISSN: 2338-9109 (online)

\title{
Dampak Kecanduan Smartphone Terhadap Kualitas Tidur Siswa SMP
}

\author{
Yupi Supartini, Puput Dwi Martiana, Titi Sulastri \\ Jurusan Keperawatan, Poltekkes Kemenkes Jakarta III \\ Email:yupi_riyanto@yahoo.com
}

\author{
Artikel history \\ Dikirim, Dec $14^{\text {th }}, 2020$ \\ Ditinjau, April $18^{\text {th }}, 2021$ \\ Diterima, April $28^{\text {th }}, 2021$
}

\begin{abstract}
Excessive smartphone use has a higher risk of sleep disturbances and affects a person's sleep quality. The purpose of this research is to determine the relationship between respondent's characteristics and smartphone addiction to the sleep quality of adolescents at Budi Cendikia Islamic School Depok. This type of research is quantitative with a descriptive analytic approach and a cross sectional research design. The population is all 359 students. Sampling in this study using stratified random sampling technique with 112 respondents. The SAS-SV questionnaire was used to measure the level of smartphone addiction, while the PSQI questionnaire was used to measure sleep quality in adolescents. The statistical test used Chi Square and Mann Whitney with a significance level of $\alpha=$ 0.05 . The results of the univariate statistical test showed that most of the respondents were male (52.7\%), 13 years old (35.7\%), had a high rate of smartphone addiction $(61.6 \%)$, and poor sleep quality (70.5\%). Meanwhile, the results of the bivariate statistical test showed that there was a significant difference between gender $(p=0.020)$ and smartphone addiction $(p=0.007)$ with sleep quality, but there was no significant difference between age and sleep quality $(p=0.938)$. This study concludes that there is a relationship between gender and smartphone addiction on students' sleep quality, but there is no relationship between age and sleep quality of students. Hence, it is necessary to limit the use of smartphones so that smartphone addiction can be minimized and sleep quality is good.
\end{abstract}

Keyword: adolescent; sleep quality; smartphone addiction.

\begin{abstract}
ABSTRAK
Penggunaan smartphone yang berlebihan atau kecanduan smartphone mempunyai risiko lebih tinggi terhadap gangguan tidur dan memengaruhi kualitas tidur seseorang. Tujuan dilakukannya penelitian yaitu untuk mengetahui hubungan karakteristik responden dan kecanduan smartphone terhadap kualitas tidur anak usia remaja di SMP Budi Cendikia Islamic School Depok. Jenis penelitian ini adalah kuantitatif dengan pendekatan deskriptif analitik dan desain penelitian cross sectional. Populasinya adalah seluruh siswa yang berjumlah 359 orang. Pengambilan sampel menggunakan teknik stratified random sampling, sebanyak 112 responden. Kuesioner SAS-SV digunakan untuk mengukur
\end{abstract}


tingkat kecanduan smartphone, sedangkan kuesioner PSQI digunakan untuk mengukur kualitas tidur pada remaja. Uji statistik menggunakan Chi Square dan Mann Whitney dengan tingkat signifikansi $\alpha=0,05$. Hasil uji statistik univariat menunjukkan sebagian besar responden berjenis kelamin laki-laki $(52.7 \%)$, berusia 13 tahun $(35.7 \%)$, memiliki tingkat kecanduan smartphone tinggi (61.6\%), dan kualitas tidur yang buruk $(70.5 \%)$. Sedangkan, hasil uji statistik bivariat menunjukkan, terdapat perbedaan yang signifikan antara jenis kelamin $(\mathrm{p}=0.020)$ dan kecanduan smartphone $(\mathrm{p}=0.007)$ dengan kualitas tidur, namun tidak terdapat perbedaan yang signifikan antara usia dengan kualitas tidur $(\mathrm{p}=0.938)$. Kesimpulan dari penelitian ini yaitu terdapat hubungan antara jenis kelamin dan kecanduan smartphone terhadap kualitas tidur siswa, namun tidak ada hubungan antara usia dan kualitas tidur siswa. Oleh karena itu, diperlukan pembatasan penggunaan smartphone agar kecanduan smartphone dapat diminimalisir dan kualitas tidur menjadi baik.

Kata kunci: kualitas tidur; kecanduan smartphone; remaja.

\section{PENDAHULUAN}

American Academy of Sleep Medicine merekomendasikan, durasi tidur optimal pada remaja usia 13-18 tahun berkisar 810 jam setiap malamnya (Paruthi et al., 2016). Namun, pada saat ini $\geq 30 \%$ remaja memiliki durasi tidur $<6$ jam setiap malam. Hal ini disebabkan pola tidur remaja yang berbeda dengan usia yang lain karena dipengaruhi oleh sejumlah perubahan di akhir masa pubertas yang menyebabkan berkurangnya waktu tidur (Putri, 2018). Selain hal tersebut, berkurangnya waktu tidur juga dipengaruhi oleh penggunaan smartphone dalam durasi waktu yang lama (Mawitjere, Onibala \& Ismanto, 2017).

Saat ini, remaja bagaikan digital pribumi, sebab mulai membagikan pemikiran dalam ruang online, mencoba mengikuti trend, hingga mencari hubungan emosional serta dukungan. Karakteristik ini, termasuk pencarian baru pada remaja, belum lagi ditambah dengan kontrol yang belum matang, sehingga remaja diposisikan pada risiko tinggi kecanduan smartphone (Riana et al., 2019). Kecanduan smartphone atau smartphone addiction merupakan kecenderungan seseorang dalam hal menggunakan smartphone melebihi batas wajar tanpa memperdulikan efek negatif yang dapat ditimbulkannya (Paramita and Hidayati, 2016). Penggunaan smartphone yang berlebihan mempunyai risiko lebih tinggi terhadap gangguan tidur dan mempengaruhi kualitas tidur seseorang (Demirci, Akgönül \& Akpinar, 2015).

Hasil studi pendahuluan yang dilakukan pada 06 Oktober 2020 terhadap 40 
siswa/i SMP Budi Cendikia Islamic School Depok, melalui pengisian survei online via google form. Didapatkan hasil bahwa seluruh siswa merupakan pengguna smartphone, 28 siswa/i (70\%) menyatakan menggunakannya dengan durasi $\geq 4$ jam 17 menit dalam sehari, dan 20 siswa (50\%) menggunakan smartphone satu jam sebelum tidur atau bahkan sampai larut malam. Hal tersebut perlu menjadi perhatian penting sebab beberapa penelitian mengenai kecanduan smartphone dan kualitas tidur umumnya hanya berfokus pada siswa SMA ataupun mahasiswa di Perguruan Tinggi saja. Padahal, Gibson et al., (2014) mengungkapkan bahwa penggunaan smartphone yang berlebihan pada usia muda (11-14 tahun) memiliki prevalensi yang lebih besar dibandingkan pada siswa/i yang lebih tua (15-18 tahun). Tujuan dari penelitian ini adalah untuk mengetahui apakah ada perbedaan kualitas tidur siswa/i di SMP Budi Cendikia Islamic School Depok yang memiliki karakteristik (jenis kelamin, usia) dan kecanduan smartphone yang berbeda.

\section{METODE PENELITIAN}

Penelitian ini merupakan studi kuantitatif observasi analitik dengan desain cross sectional. Penelitian dilakukan di SMP Budi Cendikia Islamic School Depok pada bulan September Desember. Populasinya adalah seluruh siswa/i SMP Budi Cendikia Islamic School Depok yang berjumlah 359 siswa. Jumlah sampel sebanyak 112 siswa dengan kriteria berusia $12-15$ tahun, memiliki dan/atau menggunakan smartphone, dapat berkomunikasi dengan baik, serta sehat jasmani dan rohani. Teknik pemilihan responden menggunakan teknik proportional stratified simple random sampling dengan rincian sampel kelas VII sebanyak 34 siswa, kelas VIII sebanyak 41 siswa, dan kelas IX sebanyak 37 siswa.

Variabel independen pada penelitian ini adalah karakteristik remaja (jenis kelamin, usia) dan kecanduan smartphone, sedangkan variabel dependennya adalah kualitas tidur pada anak usia remaja di SMP Budi Cendikia Islamic School Depok. Sehubungan dengan pandemik Covid-2019, persetujuan penelitian (informed consent) dan pengambilan data primer dilaksanakan secara online melalui google form dengan menggunakan 
kuesioner Pittsburgh Sleep Quality, sedangkan pengukuran data variabel kecanduan smartphone menggunakan kuesioner Smartphone Addiction ScaleShort Version (SAS-SV) untuk remaja (Arthy et al., 2019). Index (PSQI) tentang kualitas tidur (Setyowati \&
Chung, 2020)Metode analisis data yang digunakan adalah chi-square dan mann whitney dengan $\square=0,05$. Penelitian ini telah memenuhi uji etik yang diajukan pada Komisi etik Poltekkes Kemenkes Jakarta III dengan No. KEPKPKKJ3/S.113/XI/2020.

\section{HASIL DAN PEMBAHASAN}

1. Analisis Univariat

Tabel 1. Distribusi Karakteristik Responden Penelitian

\begin{tabular}{|c|c|c|c|c|}
\hline No. & Karakteristik & Kategori & Frekuensi (n) & Persentase (\%) \\
\hline \multirow[t]{2}{*}{1.} & \multirow{2}{*}{ Jenis Kelamin } & Perempuan & 53 & 47.3 \\
\hline & & Laki-laki & 59 & 52.7 \\
\hline 2. & Usia & Median 13 tahun & & \\
\hline \multirow[t]{2}{*}{3.} & \multirow{2}{*}{$\begin{array}{l}\text { Kecanduan } \\
\text { Smartphone }\end{array}$} & Tinggi & 69 & 61.6 \\
\hline & & Rendah & 43 & 38.4 \\
\hline \multirow[t]{3}{*}{4.} & \multirow[t]{2}{*}{ Kualitas Tidur } & Buruk & 79 & 70.5 \\
\hline & & Baik & 33 & 29.5 \\
\hline & Total & & 112 & 100 \\
\hline
\end{tabular}

Sumber: Data Primer, November 2020

Tabel 1 menunjukkan bahwa mayoritas responden berjenis kelamin laki-laki, berusia 13 tahun, memiliki kecanduan tinggi terhadap smartphone, dan memiliki kualitas tidur yang buruk. Hasil analisis terhadap karakteristik jenis kelamin menunjukkan bahwa sebagian besar pengguna smartphone adalah responden dengan jenis kelamin lakilaki, yaitu sebanyak 59 siswa (52.7\%). Hasil penelitian ini sejalan dengan penelitian Arthy et al. (2019) bahwa mayoritas pengguna smartphone adalah siswa laki-laki (50.3\%). Hal ini tidak sejalan dengan penelitian Lakshono (2018) dan penelitian Keswara, Syuhada, \& Wahyudi (2019) yang menunjukkan bahwa sebagian besar pengguna smartphone adalah responden dengan jenis kelamin perempuan. Menurut peneliti, adanya perbedaan lokasi penelitian menyebabkan adanya perbedaan karakteristik responden, khususnya perbedaan jenis kelamin. 
Terlepas perbedaan proporsi pengguna smartphone di atas, smartphone memiliki berbagai fungsi yang dapat memudahkan penggunanya dalam melakukan kegiatan sehari-hari. Maican et al. (2018, dalam Fischer-Grote, Kothgassner, \& Felnhofer, 2019) mengungkapkan terdapat perbedaan motif penggunaan smartphone antara anak remaja perempuan dan laki-laki. Perbedaannya adalah anak perempuan cenderung menghabiskan lebih banyak waktu pada media sosial atau pesan teks, sedangkan anak laki-laki lebih tertarik pada permainan video, berbagi media, dan pencarian di laman internet. Hal tersebut didukung oleh penelitian Arthy et al. (2019) yang dilakukan pada salah satu SMP di Medan yang menunjukkan bahwa siswi perempuan menggunakan smartphone untuk bermain media sosial, sedangkan siswa laki-laki menggunakan smartphone sebagai media hiburan (mendengarkan musik, menonton film, dan bermain game online).

Saat ini remaja bagaikan digital pribumi sebab mulai membagikan pemikiran dalam ruang online, mencoba mengikuti trend, hingga mencari hubungan emosional serta dukungan, salah satunya melalui smartphone (Riana et al., 2019).
Menurut hasil survei Kementrian Komunikasi dan Informasi (KOMINFO) didapatkan bahwa tiga puluh juta anakanak dan remaja di Indonesia merupakan pengguna internet dan media digital yang saat ini merupakan saluran komunikasi utama yang digunakan (Kominfo, 2014). Gibson et al. (2014, dalam Fischer-Grote, Kothgassner \& Felnhofer, 2019) mengungkapkan bahwa penggunaan berlebih smartphone pada usia muda (11-14 tahun) memiliki prevalensi yang lebih besar dibandingkan pada siswa/i yang lebih tua (15-18 tahun).

Hasil analisis terhadap karakteristik usia menunjukkan bahwa sebagian besar pengguna smartphone adalah responden dengan usia 13 tahun. Menurut Jarmi dan Rahayuningsih (2017) remaja pada usia ini mulai diberi kepercayaan untuk memiliki smartphone sendiri dan mulai menunjukkan eksistensi diri dengan menggunakan smartphone, sehingga cenderung lebih intens dalam menggunakan smartphone. Hal ini didukung oleh penelitian Arthy et al. (2019) yang dilakukan pada salah satu SMP di Medan yang menunjukkan bahwa mayoritas pengguna smartphone adalah remaja dengan rata-rata usia 
13.27 tahun. Hal tersebut sejalan dengan penelitian Jarmi dan Rahayuningsih (2017) yang menunjukkan bahwa mayoritas pengguna smartphone adalah remaja dengan usia 13 tahun. Remaja usia 13 tahun termasuk ke dalam kategori remaja awal. Karakteristik dari remaja awal diantaranya memiliki minat terhadap kehidupan sehari-hari, keinginan untuk belajar, dan masih bersikap kanak-kanak. Kognitifnya ditandai dengan cara berpikir yang konkret atau belum mampu untuk melihat akibat jangka panjang dari sebuah keputusan yang dibuatnya, dan moralitas masih bersifat konvensional atau sederhana (Smetana, 2011, dalam Fatkhiyah, N., Masturoh, M., \& Atmoko, D., 2020). Menurut peneliti, beberapa karakteristik tersebut dapat menyebabkan adanya perbedaan pespektif terhadap penggunaan smartphone antara remaja awal dan remaja akhir. Cara berpikir yang cenderung masih pendek membuat sekelompok remaja awal masih belum memiliki regulasi atau kontrol terhadap dampak buruk yang dapat ditimbulkan dari penggunaan smartphone secara berlebihan sehingga memiliki prevalensi yang relatif tinggi.
Hasil Analisa terhadap kualitas tidur anak usia remaja di SMP Budi Cendikia Islamic School Depok menunjukkan bahwa sebanyak 69 siswa (61.6\%) memiliki kecanduan smartphone yang tinggi. Hal ini sejalan dengan penelitian Pandey et al. tahun 2019 di Kabupaten Minahasa Selatan terhadap 153 siswa, didapati sebesar $60,1 \%$ siswa pengguna smartphone mengalami kecanduan tinggi. Hasil yang sama juga ditunjukkan oleh penelitian yang dilakukan oleh Riana pada tahun 2019 di Kabupaten Lombok Barat terhadap 150 siswa, didapati $78 \%$ siswa mengalami kecanduan tinggi terhadap smartphone (Riana et al., 2019).

Griffiths (2011, dalam Putri, 2018) mengungkapkan bahwa kecanduan smartphone adalah penggunaan yang terlalu lama dalam menggunakan smartphone sehingga mengganggu kehidupan sehari-hari penggunanya. Seseorang dianggap mengalami kecanduan smartphone apabila durasi penggunaan smartphone menjadi patologis, yaitu mencapai 33.17 menit lebih lama dari penggunaan yang yang direkomendasikan, yaitu 4 jam 17 menit dalam sehari (Fischer-Grote, Kothgassner \& Felnhofer, 2019). 
Menurut peneliti, walaupun smartphone memiliki berbagai manfaat untuk menunjang kehidupan sekolah pada siswa SMP, namun hal tersebut berpotensi untuk menyebabkan terjadinya kecanduan smartphone. Kecanduan smartphone memiliki dampak negatif bagi kesehatan, diantaranya dapat memicu ketidaknyamanan fisik, seperti sakit kepala $(37,7 \%)$, sakit mata $(28,9 \%)$, dan keluhan telinga $(42,9 \%)$ setelah penggunaan smartphone yang berlebihan (Mushroor, Haque \& Amir, 2019). Jika fenomena kecanduan smartphone dibiarkan dalam jangka waktu yang lama, maka dapat menyebabkan kelainan perilaku yang maladaptif, mengganggu kinerja di sekolah, mengurangi interaksi sosial dikehidupan nyata, pengabaian kehidupan pribadi, perubahan mood, gangguan mental, dan gangguan hubungan interpersonal pada siswa usia remaja (Putri, 2018).

Hasil analisa terhadap kualitas tidur anak usia remaja di SMP Budi Cendikia Islamic School Depok menunjukkan bahwa sebanyak 79 siswa $(70.5 \%)$ memiliki kualitas tidur yang buruk. Hasil penelitian ini sesuai dengan penelitian Keswara, Syuhada dan Wahyudi pada tahun 2019 bahwa sebanyak 64.7\% siswa pengguna smartphone memiliki kualitas tidur yang buruk. Hasil yang serupa juga ditunjukkan oleh penelitian Riana et al. tahun 2019 bahwa $60 \%$ siswa pengguna smartphone memiliki kualitas tidur yang buruk. Hasil ini tidak sejalan dengan penelitian Putri yang menunjukkan bahwa rasio kualitas tidur pada siswa yang menggunakan smartphone memiliki proporsi kualitas tidur yang baik (51\%) lebih besar dibanding kualitas tidur yang buruk (49\%). Menurut peneliti, hal ini disebabkan oleh karakteristik responden yang berbeda dan faktor lain yang dapat memengaruhi kualitas tidur seseorang. Faktor-faktor tersebut yaitu penyakit, lingkungan, gaya hidup, stres emosional, zat stimulan, diet, merokok, dan motivasi.

Penggunaan smartphone yang berlebihan mempunyai risiko lebih tinggi terhadap gangguan tidur dan memengaruhi kualitas tidur seseorang (Demirci, Akgönül \& Akpinar, 2015). Kualitas tidur yang buruk akan menimbulkan imbas negatif terhadap Kesehatan karena dapat meningkatkan 
risiko terjadinya diabetes, hipertensi, stroke, depresi, kanker, dan disfungsi imun (Nurfadilah H, Andono Ahmad \& Julia, 2017). Selain itu, remaja dengan kualitas tidur yang buruk dapat memberikan pengaruh terhadap prestasi akademiknya, hal ini disebabkan oleh penurunan motivasi untuk turut andil dalam kegiatan di sekolah, penurunan kewaspadaan dan konsentrasi, menjadi cepat marah, impulsif, serta menunjukkan kesedihan (Ya'kub, Widodo \& Putri, 2017).

2. Analisis Bivariat

Tabel 2. Uji Chi Square Karakteristik Responden: Jenis Kelamin dan Kualitas Tidur

\begin{tabular}{lccccccc}
\hline \multirow{2}{*}{ Jenis Kelamin } & \multicolumn{3}{c}{ Kualitas Tidur } & \multicolumn{3}{c}{ Total } \\
\cline { 2 - 7 } & \multicolumn{2}{c}{ Buruk } & \multicolumn{2}{c}{ Baik } & \multicolumn{3}{c}{} \\
\cline { 2 - 6 } & $\mathrm{n}$ & $\%$ & $\mathrm{n}$ & $\%$ & $\mathrm{n}$ & \\
\hline Perempuan & 43 & 81.1 & 10 & 18.9 & 53 & 47.3 \\
\hline Laki-laki & 36 & 61 & 23 & 39 & 59 & 52.7 \\
\hline Total & 79 & 70.5 & 33 & 29.5 & 112 & 100 \\
\hline & Uji Chi Square $\mathrm{p}=0.020 ;$ OR $=2.747$ \\
\hline
\end{tabular}

Sumber: Data Primer, November 2020

Tabel 2 menunjukkan hasil uji statistik Chi Square dengan p-value $0.020(\alpha=<$ 0.05) dan nilai $\mathrm{OR}=2.747$. $\mathrm{H}_{0}$ ditolak dan $\mathrm{H}_{1}$ diterima, artinya terdapat perbedaan atau hubungan yang signifikan antara jenis kelamin dengan kualitas tidur anak usia remaja di SMP Budi Cendikia Islamic School Depok. Siswa yang berjenis kelamin perempuan memiliki peluang 2.747 kali lebih besar untuk mengalami kualitas tidur buruk dibandingkan siswa yang berjenis kelamin laki-laki.

Penelitian ini sejalan dengan penelitian de Souza et al. (2018) bahwa terdapat hubungan antara jenis kelamin dengan kualitas tidur dan perempuan memiliki kecenderungan untuk mengalami kualitas tidur yang buruk sebesar 12.6 kali dibandingkan dengan laki-laki $(\mathrm{p}=$ 0.000; OR $=12.58)$. Hal ini sesuai dengan penelitian Lee et al. (2020) bahwa mayoritas remaja perempuan memiliki kualitas tidur buruk yang lebih tinggi $(46 \%)$ dibanding remaja laki-laki $(35.6 \%)$.

Dampak perbedaan jenis kelamin terhadap kualitas tidur dipengaruhi oleh berbagai faktor, termasuk faktor fisiologis dan psikologis. Berdasarkan faktor fisiologis, perubahan hormonal selama siklus menstruasi pada perempuan memengaruhi ritme sirkadian dan formasi tidur yang sering 
menyebabkan terjadi gangguan tidur serta memperburuk kualitas tidur yang buruk. Selain itu, perubahan hormonal seperti depresi, kecemasan, dan perasaan mudah tersinggung pada perempuan dapat menyebabkan penurunan kualitas tidur. Berkenaan dengan faktor psikososial, perempuan cenderung lebih rentan terhadap stressor. Hal ini menyebabkan terjadinya peristiwa yang kurang menyenangkan sehingga dapat berkontribusi pada masalah tidur termasuk insomnia dan gangguan kualitas tidur pada perempuan (Lee et al., 2020).

Penelitian Mong, Cusmano dan Mong (2016) juga turut mendukung penelitian Lee bahwa faktor independen pada tidur seperti suasana hati dapat berkontribusi pada persepsi kualitas tidur yang buruk pada seorang perempuan, dengan syarat perempuan tersebut tidak memiliki gangguan tidur. Dalam studi polisomnografi (PSG) terkait perempuan dengan sindrom pramenstruasi, penilaian subjektif kualitas tidur yang buruk memiliki korelasi dengan kecemasan yang tinggi dan kecenderungan untuk sering terbangun pada dini hari (Mong, Cusmano, dan Mong, 2016). Hal ini menunjukkan bahwa penilaian kualitas tidur sangat dipengaruhi oleh kecemasan, gejala depresi, dan gangguan afektif. Oleh karena itu, menurut peneliti dibutuhkan studi atau penelitian khusus yang lebih mendalam terkait intensitas tidur yang diukur melalui EEG kuantitatif atau spektral analisis pada perempuan terutama pada siswi usia remaja di SMP sebab pada masa ini seorang remaja awal baru mengalami adanya pertumbuhan sekunder, salah satunya menstruasi.

Tabel 3. Uji Mann Whitney Usia dan Kualitas Tidur

\begin{tabular}{llllc}
\hline & $\begin{array}{c}\text { Kategori Kualitas } \\
\text { Tidur }\end{array}$ & $\mathrm{n}$ & $(\%)$ & Mean Rank \\
\hline \multirow{3}{*}{ Usia } & Kualitas Tidur Buruk & 79 & 70.5 & 56.35 \\
\cline { 2 - 5 } & Kualitas Tidur Baik & 33 & 29.5 & 56.85 \\
\cline { 2 - 4 } & Total & 112 & 100 & \\
\hline & Uji Mann Whitney $\mathbf{p}=\mathbf{0 . 9 3 8}$ &
\end{tabular}

Sumber: Data Primer, November 2020

Tabel 3 menunjukkan hasil uji statistik Mann Whitney dengan p-value 0.938 ( $\alpha$ $=<0.05)$, artinya $\mathrm{H}_{0}$ diterima dan $\mathrm{H}_{1}$ ditolak atau tidak terdapat perbedaan atau hubungan yang signifikan antara usia dengan kualitas tidur anak usia remaja di SMP Budi Cendikia Islamic School Depok. 
American Academy of Sleep Medicine merekomendasikan, durasi tidur optimal pada remaja usia 13-18 tahun berkisar 810 jam setiap malamnya (Paruthi et al., 2016). Selama tidur terdapat proses penting yang terjadi untuk menunjang fungsi kesehatn otak dan kesehatan fisik secara utuh terutama bagi anak-anak dan remaja. Menurut Ohayon, terdapat beberapa indikator kualitas tidur yang baik bagi remaja: 1) latensi tidur berkisar 0-15 menit atau 16-30 menit, 2) gangguan tidur seperti terbangun pada dini hari tidak lebih dari 1x dalam lima menit, 3) onset bangun tidur $\leq 10$ menit atau 11-20 menit, 4) efisiensi tidur $\geq$ 95\% atau 85-94\%, 5) tahapan REM 11$20 \%$, NREM $1 \leq 5 \%$, NREM $2>81 \%$, NREM 3 20-25\%, 6) Tidur siang/24 jam tidak lebih dari $1 \mathrm{x}$ dengan durasi $\leq 20$ menit (Ohayon et al., 2017).
Hasil analisa menunjukkan sebanyak 79 siswa $(70.5 \%)$ memiliki kualitas tidur buruk, sedangkan hasil uji statistik Mann Whitney menunjukkan p-value 0.938 dengan $\alpha=<0.05$, artinya $\mathrm{H}_{0}$ diterima dan $\mathrm{H}_{1}$ ditolak atau tidak terdapat perbedaan kualitas tidur berdasarkan usia. Hal ini berarti tidak ada hubungan yang signifikan antara usia dengan kualitas tidur anak usia remaja di SMP Budi Cendikia Islamic School Depok. Menurut opini peneliti hasil tersebut didasari oleh interval usia responden masih dalam satu kategori (remaja awal), sehingga tidak ada perbedaan yang berarti antara usia dengan kualitas tidur. Pendapat tersebut sesuai dengan teori yang dikemukakan oleh Audrey Berman, Shirlee J. Snyder (2015) bahwa usia tidak termasuk ke dalam faktor risiko yang dapat memengaruhi tidur seseorang.

Tabel 4. Uji Chi Square Kecanduan Smartphone dan Kualitas Tidur

\begin{tabular}{lcccccc}
\hline \multirow{2}{*}{$\begin{array}{l}\text { Secanduan } \\
\text { Smartphone }\end{array}$} & \multicolumn{3}{c}{ Kualitas Tidur } & \multicolumn{3}{c}{ Total } \\
\cline { 2 - 6 } & $\mathrm{n}$ & $\%$ & $\mathrm{n}$ & $\%$ & $\mathrm{n}$ & $\%$ \\
\hline Kecanduan Tinggi & 55 & 79.7 & 14 & 20.3 & 69 & 61.6 \\
\hline Kecanduan Rendah & 24 & 55.8 & 19 & 44.2 & 43 & 38.4 \\
\hline Total & 79 & 70.5 & 33 & 29.5 & 112 & 100 \\
\hline & Uji Chi Square $\mathrm{p}=0.007 ;$ OR $=3.110$ & \\
\hline
\end{tabular}

Sumber: Data Primer, November 2020

Tabel 4 menunjukkan hasil uji statistik Chi Square dengan p-value $0.007(\alpha=<$
0.05) dan $\mathrm{OR}=3.110$, artinya $\mathrm{H}_{0}$ ditolak dan $\mathrm{H}_{1}$ diterima. Hal ini berarti terdapat 
perbedaan atau hubungan yang signifikan antara kecanduan smartphone dengan kualitas tidur, dimana remaja dengan kecanduan smartphone yang tinggi memiliki peluang sebesar 3.110 kali untuk mengalami kualitas tidur yang buruk.

Hasil penelitian ini sejalan dengan penelitian yang dilakukan oleh Putri (2018) terhadap 75 responden yang menunjukkan hasil signifikansi sebesar 0.001 ( $\mathrm{p}<0.005)$, artinya terdapat hubungan antara kecanduan smartphone dengan kualitas tidur siswa. Penelitian Putri juga menunjukkan arah korelasi yang negatif (-0.372), hal ini berarti semakin tinggi kecanduan smartphone maka kualitas tidur yang didapatkan akan semakin buruk. Hal ini sesuai dengan penelitian yang dilakukan oleh Pandey et al. (2019) terhadap 153 responden, yaitu terdapat hubungan yang signifikan antara kecanduan smartphone dengan kualitas tidur $(\mathrm{p}=0.000 ; \alpha=$ 0.05). Berbeda dengan penelitian Putri dan Pandey, penelitian Yolanda (2019) di Ungaran terhadap 102 responden menunjukkan bahwa tidak ada hubungan yang signifikan antara screen based activity dengan kualitas tidur $(\mathrm{p}=0.216)$. Menurut peneliti, hal ini disebabkan oleh karakteristik responden yang berbeda dan faktor lain yang dapat memengaruhi kualitas tidur seseorang. Faktor-faktor tersebut yaitu penyakit, lingkungan, gaya hidup, stres emosional, zat stimulan, diet, merokok, dan motivasi.

Menurut Riana et al. (2019) saat ini remaja bagaikan digital pribumi, sebab mulai membagikan pemikiran dalam ruang online, mencoba mengikuti trend, hingga mencari hubungan emosional serta dukungan. Karakteristik ini, termasuk pencarian baru pada remaja, belum lagi ditambah dengan kontrol yang belum matang, sehingga remaja diposisikan pada risiko tinggi kecanduan smartphone (Riana et al., 2019). Menurut Griffiths (2011, dalam Putri, 2018) kecanduan smartphone diartikan sebagai penggunaan yang terlalu lama dalam menggunakan smartphone sehingga mengganggu kehidupan seharihari penggunanya. Penggunaan smartphone yang berlebihan mempunyai risiko lebih tinggi terhadap gangguan tidur dan memengaruhi kualitas tidur seseorang (Demirci, Akgönül \& Akpinar, 2015). Hal ini dikarenakan smartphone dapat memancarkan sinar biru atau blue light. Menggunakan smartphone sebelum tidur dapat menghambat produksi melatonin, yaitu hormon yang menstimulus rasa kantuk. 
Penggunaan smartphone pada jam tidur dapat memengaruhi kualitas tidur menjadi buruk, efisiensi tidur menurun dan mulainya onset untuk tidur menjadi lebih lama (Riana et al., 2019). Ambarwati (2017) mengungkapkan bahwa fisiologi tidur diatur di pusat otak pada bagian RAS (Reticular Activating System) dan BSR (Bulbar Synchronizing Region). BSR akan aktif ketika kondisi lingkungan kondusif, sedangkan ketika remaja menggunakan smartphone maka sistem RAS akan aktif karena mendapat stimulus eksternal seperti cahaya, suara, dan getaran dari smartphone sehingga menyebabkan remaja tetap terjaga pada malam hari. Menurut Amalina et al. (2015, dalam Yolanda, 2019) toleransi durasi penggunaan smartphone sebelum tidur adalah 30 menit, sedangkan menurut Nurfadhilah et al. (2017 dalam Yolanda, 2019) perilaku screen based activity sebelum tidur baiknya tidak lebih dari 2 jam (Yolanda, 2019). Penggunaan smartphone yang melebihi batas toleransi akan berdampak pada kualitas tidur yang buruk karena seseorang membutuhkan waktu sekitar 10-30 menit untuk pre-sleep (Potter \& Perry, 2006, dalam Jarmi \& Rahayuningsih, 2017). Remaja dengan kualitas tidur buruk dapat memberikan pengaruh terhadap prestasi akademiknya, hal ini disebabkan oleh penurunan motivasi untuk turut andil dalam kegiatan di sekolah, penurunan kewaspadaan dan konsentrasi, menjadi cepat marah, impulsif, serta menunjukkan kesedihan (Ya'kub, Widodo \& Putri, 2017).

\section{SIMPULAN DAN SARAN}

\section{Simpulan}

Berdasarkan hasil penelitian yang dilakukan pada 112 anak usia remaja di SMP Budi Cendikia Islamic School Depok yang menggunakan smartphone didapatkan kesimpulan bahwa sebagian besar responden berjenis kelamin laki-laki, berusia 13 tahun, memiliki kecanduan smartphone yang tinggi, dan memiliki kualitas tidur yang buruk. Sedangkan hasil analisis bivariat menunjukkan bahwa terdapat hubungan yang signifikan antara jenis kelamin dan kecanduan smartphone dengan kualitas tidur, namun tidak terdapat hubungan yang signifikan antara usia dengan kualitas tidur.

\section{Saran}

a. Bagi Siswa

Diharapkan para siswa dapat membatasi penggunaan 
smartphone. Penggunaan

smartphone setidaknya hanya $\leq 4$ jam 17 menit dalam 24 jam. Selain itu, siswa diharapkan dapat melakukan manajemen waktu tidur 8-10 jam per malam dan menghindari penggunaan smartphone minimal 30 menit sebelum tidur agar tercipta tidur yang berkualitas.

b. Orang Tua Siswa

Orang tua atau wali murid diharapkan lebih bijak dalam memfasilitasi remaja dengan smartphone. Orang tua atau wali murid dapat mengajak remaja untuk melakukan kegiatan positif bersama dan menetapkan waktu tidur yang tegas.

c. Penelitian Keperawatan

Hasil penelitian ini dapat digunakan sebagai data awal dan acuan bagi peneliti lain untuk melakukan penelitian eksplorasi atau pengembangan mengenai hubungan kecanduan smartphone terhadap kualitas tidur pada anak usia remaja terutama siswa SMP. Penelitian berkelanjutan dimaksudkan untuk menganalisis secara lebih detail terkait faktorfaktor yang dapat memengaruhi kecanduan smartphone, namun belum diteliti pada penelitian ini. Faktor-faktor tersebut diantaranya, faktor durasi penggunaan smartphone, faktor pola penggunaan smartphone, faktor sekolah, faktor keluarga, serta faktor hubungan sosial responden. Penelitian terkait kualitas tidur dengan menggunakan EEG kuantitatif atau spektral analisis pada perempuan juga sangat dianjurkan sebab dapat memberikan dampak positif terhadap pengembangan ilmu pengetahuan secara bermakna.

d. Pelayanan Keperawatan

Hasil penelitian ini dapat dijadikan motivasi bagi praktisi keperawatan untuk melakukan pengembangan standar operasional praktik keperawatan terkait dengan pemberian asuhan keperawatan kepada remaja yang mengalami kecanduan smartphone tinggi dan juga kualitas tidur yang buruk

e. Pendidikan Keperawatan

Hasil penelitian ini dapat digunakan sebagai referensi bagi mahasiswa keperawatan untuk melakukan analisis berbasis studi kasus sehingga dapat memacu 
daya berfikir kritis ilmiah mahasiswa dalam memberikan asuhan keperawatan terkait kecanduan smartphone dan kualitas tidur pada anak usia remaja.

\section{DAFTAR RUJUKAN}

Ambarwati, R. 2017. Tidur, Irama Sirkadian dan Metabolisme Tubuh. Jurnal Keperawatan. (Online), X(1), pp. 42-44, (http://www.litbang.kemkes.go.id:8 080/handle/123456789/33428), diakses 24 September 2020.

Arthy, C. C. et al. 2019. Indonesian version of Addiction Rating Scale Of Smartphone Usage Adapted From Smartphone Addiction ScaleShort Version (SAS-SV) in Junior High School. Open Access Macedonian Journal of Medical Sciences. (Online), 7 (19), pp. 3235-3239,

(https://www.researchgate.net/publi cation/338184653_Indonesian_Ver sion_of_Addiction_Rating_Scale_o f_Smartphone_Usage_Adapted_fro m_Smartphone_Addiction_ScaleShort_Version_SAS-

SV_In_Junior_High_School), diakses 26 September 2020.

Audrey Berman, Shirlee J. Snyder, dan G. F. 2015. Kozier \& Erb's Fundamentals of Nursing Concepts, Process, and Practice. 10th edn, Kozier \& Erb's Fundamentals of Nursing, Global Edition. 10th edn. USA: Pearson.
Demirci, K., Akgönül, M. and Akpinar, A. 2015. Relationship of Smartphone Use Severity with Sleep Quality, Depression, and Anxiety in University Students. Journal of Behavioral Addictions. (Online), 4(2), pp. 85-92, (https://pubmed.ncbi.nlm.nih.gov/2 6132913/), diakses 19 September 2020.

Fatkhiyah, N., Masturoh, M., \& Atmoko, D. 2020. Edukasi Kesehatan Reproduksi Remaja. Jurnal Abdimas Mahakam. (Online), 4(1), 84-89, (http://journal.uwgm.ac.id/index.ph p/abdimasmahakam/article/view/77 6), diakses 01 November 2020.

Fischer-Grote, L., Kothgassner, O. D. and Felnhofer, A. 2019. Risk Factors For Problematic Smartphone Use In Children and Adolescents: A Review Of Existing Literature. Neuropsychiatrie Journa. (Online), 33(4), pp. 179-190. doi: 10.1007/s40211-019-00319-8, (https://link.springer.com/article/10 .1007/s40211-019-00319-8), diakses 05 Oktober 2020.

Gibson W., Lopez-FernandezO, Honrubia SerranoL, Freixa-Blanxart M. 2014. Prevalence of Problematic Mobile Phone Use In British Adolescents. Cyberpsychol Behav Soc Netw Journal. 2014;17(2):91-8, (https://www.liebertpub.com/doi/ab s/10.1089/cyber.2012.0260), diakses 01 November 2020.

Jarmi, A. and Rahayuningsih, S. I. 2017. Hubungan Penggunaan Gadget dengan Kualitas Tidur pada Remaja. Jurnal Keperawatan. (Online), pp. $1-7$, (http://www.jim.unsyiah.ac.id/FKe 
p/article/view/3872), diakses 28 September 2020.

Keswara, U. R., Syuhada, N. and Wahyudi, W. T. 2019. Perilaku Penggunaan Gadget dengan Kualitas Tidur pada Remaja. Holistik Jurnal Kesehatan. (Online), 13(3), pp. 233-239. doi: 10.33024/hjk.v13i3.1599,

(https://core.ac.uk/download/pdf/23 7009139.pdf), diakses 02 Agustus 2020.

Kominfo. 2014. Riset Kominfo dan UNICEF Mengenai Perilaku Anak dan Remaja dalam Menggunakan Internet, Kominfo. Available at: https://kominfo.go.id/content/detail/ 3834/siaran-pers-no-

17pihkominfo22014-tentang-risetkominfo-dan-unicef-mengenaiperilaku-anak-dan-remaja-dalammenggunakan-

internet/0/siaran_pers (Diakses 12 September 2020).

Lakshono, B. D. 2018. Hubungan Penggunaan Smartphone dengan Kualitas Tidur Pada Remaja Di SMA Negeri 2 Kota Bangun. Kalimantan Timur: UMKT. Skripsi. (Online), (https://dspace.umkt.ac.id/handle/4 63.2017/562), diakses 13 Oktober 2020.

Lee, S. Y. et al. 2020. Factors Associated With Poor Sleep Quality in The Korean General Population: Providing Information From The Korean Version of the Pittsburgh Sleep Quality Index. Journal of Affective Disorders. Elsevier B.V. (Online), pp. 49-58, (https://www.sciencedirect.com/sci ence/article/pii/S016503271932170 6), diakses 01 Oktober 2020.
Mawitjere, O., Onibala, F., \& Ismanto, Y. 2017. Hubungan Lama Penggunaan Gadget dengan Kejadian Insomnia pada Siswa Siswi Di SMA Negeri 1 Kawangkoan. Jurnal Keperawatan UNSRAT. (Online), 5(1), p. 104905 , (https://ejournal.unsrat.ac.id/index. php/jkp/article/view/15827), diakses 01 Oktober 2020.

Mong, J. A., Cusmano, D. M. and Mong, J. A. 2016. Sex Differences in Sleep: Impact of Biological Sex and Sex Steroids. Journal of Royal Society Publishing.

(Online), (https://royalsocietypublishing.org/ doi/abs/10.1098/rstb.2015.0110), diakses 03 Oktober 2020.

Mushroor, S., Haque, S. and Amir, R. A. 2019. The Impact of Smartphones and Mobile Devices on Human Health and Life. International Journal Of Community Medicine And Public Health. (Online), 7(1), p. 9. doi: 10.18203/23946040.ijcmph20195825,

(https://pdfs.semanticscholar.org/b2 cb/f9e9b597dbdbae91fd513b87e47 5b0bff399.pdf), diakses 03 November 2020.

Nurfadilah H, S., Andono Ahmad, R. and Julia, M. 2017. Aktivitas fisik dan screen based activity dengan pola tidur remaja di Wates. BKM Journal of Community Medicine and Public Health. (Online), 33(7), pp. 343-350, (https://pdfs.semanticscholar.org/ab a3/3fca79d158db42edbf14074d62a 7da7854a3.pdf), diakses 09 Oktober 2020 . 
Ohayon, M. et al. 2017. National Sleep Foundation's Sleep Quality Recommendations: First Report. Sleep Health. National Sleep Foundation. (Online), 3(1), pp. 619 ,

(https://www.sciencedirect.com/sci ence/article/pii/S235272181630130 9), diakses 02 Oktober 2020.

Pandey, C. M. et al. 2019. Hubungan Antara Kecanduan Smartphone dengan Kualitas Tidur Pada Siswa SMA Negeri 1 Maesaan Kabupaten Minahasa Selatan. Jurnal KESMAS. (Online), 8(2), pp. 22-29, (https://ejournal.unsrat.ac.id/index. php/kesmas/article/view/23935), diakses 02 Oktober 2020.

Paramita, T. and Hidayati, F. 2016. Smartphone Addiction Ditinjau dari Alienasi Pada Siswa Sman 2 Majalengka. Jurnal Karya Ilmiah S1 Undip. (Online), 5(4), pp. 858-862, (https://ejournal3.undip.ac.id/index. php/empati/article/view/15456), diakses 02 Oktober 2020.

Paruthi, S. et al. 2016. Consensus Statement of the American Academy of Sleep Medicine on the Recommended Amount of Sleep for Healthy Children: Methodology and Discussion. Journal of Clinical Sleep Medicine. (Online), 12(11), pp. $1549-1561$ (https://jcsm.aasm.org/doi/abs/10.5 664/jcsm.6288), diakses 29 September 2020.

Putri, A. Y. 2018. Hubungan Kecanduan Smartphone Dengan Kualitas Tidur Pada Remaja. Surabaya: UIN Sunan Ampel Surabaya. doi: 10.1093/imamci/dnt037.
Riana, Y. et al. 2019. Hubungan antara Penggunaan Smartphone dengan Kualitas Tidur pada Siswa SMAN 1 Mataram di Kota Mataram dan SMAN 1 Gunungsari di Kabupaten Lombok Barat, Jurnal Kedokteran. (Online), 8(3), pp. 33-39, (http://jku.unram.ac.id/article/view/ 360), diakses 30 September 2020.

Setyowati, A. and Chung, M. H. 2020. Validity and Reliability of the Indonesian Version of the Pittsburgh Sleep Quality Index in Adolescents. International Journal of Nursing Practice. (Online), pp. 17 ,

(https://onlinelibrary.wiley.com/doi /abs/10.1111/ijn.12856), diakses 15 Oktober 2020.

de Souza, J. C. et al. 2018. Gender Differences in Sleep Habits and Quality and Daytime Sleepiness in Elementary and High School Teachers. Chronobiology International. (Online), Taylor \& Francis, 35(4), pp. 486-498, (https://www.tandfonline.com/doi/a bs/10.1080/07420528.2017.141592 1), diakses 11 Oktober 2020.

Ya'kub, Widodo, D. and Putri, R. S. M. 2017. Gangguan Tidur Berhubungan Dengan Prestasi Belajar Pada Anak Sekolah Dasar Negeri 01 Sumber Sekar Kecamatan Dau Kabupaten Malang. Nursing News, 2. (Online), pp. 270-280, (https://publikasi.unitri.ac.id/index. php/fikes/article/view/471), diakses 20 Oktober 2020.

Yolanda, A. A. et all (2019) 'Hubungan Aktivitas Fisik, Screen Based Activity dan Sleep Hygiene dengan Kualitas Tidur pada Remaja Usia 15-18 Tahun (Studi Pada Siswa Di 
Sma Negeri 1 Ungaran). Jurnal

Kesehatan Masyarakat. (Online),

$7(1)$, pp. 123-130, diakses 11

Oktober 2020. 